\title{
Flexible Product Platform Based on Design Parameters
}

\author{
Qian Ma, Runhua Tan, Ping Jiang, Bingyi Yao, and Xinjun Hui \\ Department of Mechanical Engineering, Hebei University of Technology \\ Tianjin, China \\ honeymaqian@yahoo.com.cn
}

\begin{abstract}
In the times of mass customization mode, enterprises face more changeable market demand. The traditional product platform can not meet the needs of all customer, therefore the flexible product platform is particularly important. But the method of parametric design is needed to make product platform to be changed rapidly based on flexible product platform. This paper connects parametric design and flexible product platform, and a design process based on flexible product platform with parametric design is developed. Finally the process is applied to the design of belt conveyor, and the flexible product platform with parametric design is set up.
\end{abstract}

Keywords: flexible product platform, parameterized Mass Customization, belt conveyor.

\section{Introduction}

The customers' demand for the product is continuously improving with the generation and development of mass customization. Diversified needs form customer leads to a large number of uncertainties, so in order to meet customer's different customization requirements enterprises have carried on variant design on the basis of the original product. In general, much business depend on common product platform to design new product, but the continuous improvement of complexity results in a large number of parts and components should be repeated designed in deformation design, this can reduce efficiency, increase costs and complexity of the production process. The current design method for platform placed more emphasis on the common structure of products share. However, the shared degree is inversely proportional to the market segmentation scope; this resulted in the contradiction between the generality and flexibility of platform structure. Only by understanding these uncertainties fully and reducing their negative impact, can enterprises develop a product platform with highefficiency and high-quality.

So, this paper introduces a design method of flexible product platform for the products which have the same function. We should take into account some uncertainty in the future development of product when we begin to design a product platform, at the same time, add the parameterized design method to the design of product platform, finally a Parameterized flexible product platform is built which is based on these factors above. It can help the enterprise produce many kinds of 
variable products using the same product platform to meet customers' individual requirements on performance, appearance, size add so on. This can extend the life of product platform, reduce costs and improve efficiency.

\section{Design Processes of Flexible Product Platform Based on Parameters}

First introduce and study the related Concepts:

A product platform is the common technological base from which a product family is derived through modification and instantiation of the product platform to target specific market niches.

Parametric Design is for the parts or components, whose shape is case-hardened relatively; we can use a set of parameters to constrain the structure size and topology of the model. The parameters have an explicit correspondence with the controlled size of design object. A typical model can be driven when given it different sequence values of parameters to get the part model which meet requirements of the designer, this can meet the different needs of working performance by changing local structural forms and parameters of existing products.

Flexibility is desirable when a system of any kind is faced with exogenous uncertainty, but must be implemented carefully to minimize undesirable side effects.

\subsection{The Research for Design Methods of Product Platform}

According to the different ways to achieve the product characteristics in the product family, the design of current product platform can be divided into two parts: the design of product platform based on modular and the design of product platform based on adjustable variables [1].

The design method of product platform based on modular is mainly aimed at the product variants with different functions, it could derive products which meet different subdivided markets by adding, removing, replacing, modifying one or more modules in the platform. The main steps are: draw the product's features flow diagram at first, and then use the principle of third-rate to mark off the function modules of product, finally, get a modularized product platform through correlation analysis or modularity matrix.

The design method of product platform based on adjustable variables is mainly applied to products which have the same functions; it can achieve a series of product family by changing some features. The representative method is Product Platform Concept Exploration Method, (PPCEM) proposed by Simpson [2]. The method determines the appropriate scale factor by dividing the market grid, and then extended product platform in order to achieve the parametric design of product platform and personality structure.

The two methods mentioned above are main methods to achieve the design of product family based on the product platform. They have their own advantages, but have their own scope of application. Design using flexible product platform combines the advantages of both methods. The flexible product platform can be defined as an organization or system that consists of public and flexible elements (component, 
process or interface), we can achieve a range of product variants and product family by adjusting the value of flexible elements dynamically without changing common elements. When designing a flexible product platform, we should find the public modules of a series of variable products by marking off all modules of products at first, then determine the flexible structure of products by extracting the main design parameters and mapping to the physical structure according to the market analysis. Finally adjusting the main attribute parameter of flexible modules dynamically could achieve the products which meet the different market segments [3].

The following Figure 1 shows the outline and framework of the design process of flexible product platform brought forward by Suh [4].

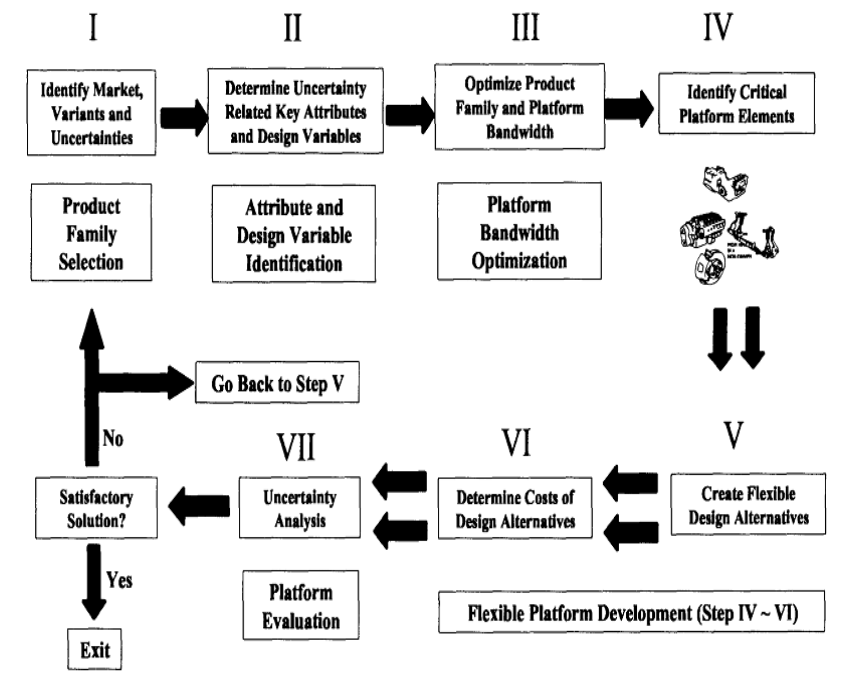

Fig. 1. Design process of flexible product platform brought forward by Suh

\subsection{Design Method for Parametric Flexible Product Platform}

According to the design process of flexible product platform, adding the variant design and parameterization, we can get a design method of flexible product platform based on parameter [5].The step are as following.

Step 1: Demarcate Market segments

Mark out the market segments, and constitute market segmentation grid.

In order to survive, enterprises must find markets, and then, define and segment them. Figure 2 shows a conceptual framework of a market segment, the entire market is divided into a number of market segments along horizontal and vertical. Each horizontal segment represents consumers of some products, while the vertical segment is divided into three grades, they are high-end, mid and low-end. Through dividing horizontal and vertical grid, a large market was divided into a number of market units. 


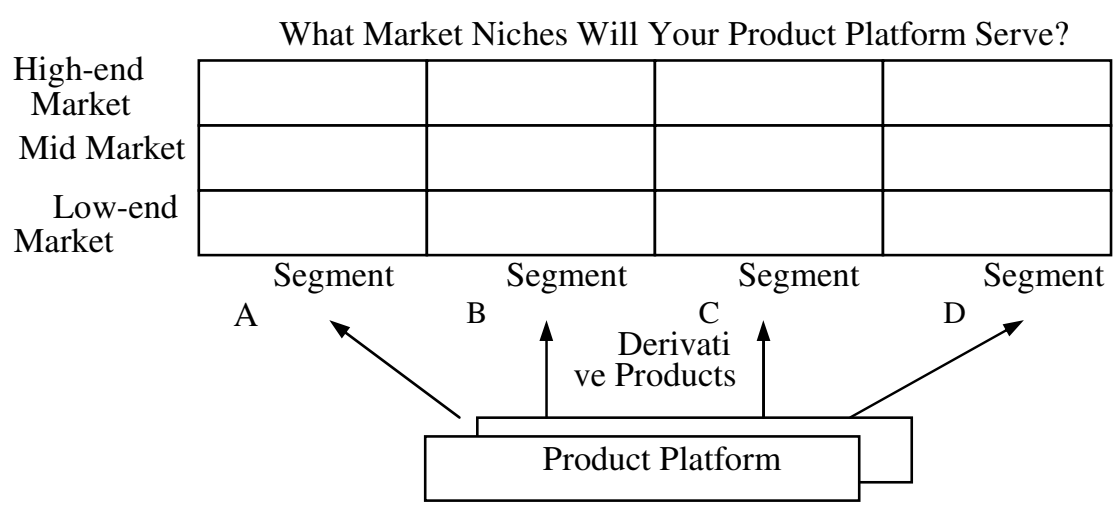

Fig. 2. Conceptional frame of market segmentation

During segmenting market and formulating the optimal platform strategy, designers need to identify the following variables:

Market segments of product: $\mathrm{M}=\{\mathrm{M} 1, \mathrm{M} 2, \ldots, \mathrm{Mi}\}$

Product variants: $\mathrm{P}=\{\mathrm{P} 1, \mathrm{P} 2, \ldots, \mathrm{Pj}\}$

Step 2: Analysis of uncertainty, determine the main parameters which affect performance, and identify uncertainties

Now we first introduce the method of DFV [5] .

There are two objects to use this method. One is to develop a method about structure designing. It is useful to help development teams to design a platform architecture which robust to future changing. The other is to define a measure of coupling between components. This measure includes the physical interactions between the components and indicates how likely one component affects another.

There are two indexes, Generational Variety Index (GVI) and Concept Index (CI). The generational variety index is an indicator of how likely the components of a design are to change over the life of the product platform. The concept index is a measure of how tightly coupled the design is.

The design steps for DFV method are as follows:

(1) Generate GVI and CI for the design.

(2) Order the components based on GVI.

(3) Determine where to focus effort.

It is a very important step to identify the uncertainty of product development in the future in programming a flexible product platform, because the position and using method of flexibility on the product platform depend on the uncertainty in future development .

Uncertainty can be divided into knowable-uncertainty and unknowable uncertainty. Knowable uncertainty can be got approximate solution using past experience and data or to be predicted by collecting experts' advice and the motive of consumes. Unknowable uncertainty could be found by using DFV. 
Step 3: Optimization uncertainty, determine the range of uncertainty to get the bandwidth of platform, then optimization the product family.

During designing a product family, Simpson put the scale factor into robust design, as shown in Figure 3. Scale factor is a factor around which a product platform can be "scaled" or "stretched" to realize derivative products within a product family.

Correspondingly, two types of scale factors can be identified-parametric and conceptual/configurational related to the type of scaling. The relationship between each type of scale factor and the three types of leveraging are as follows:

Vertical leveraging: parametric scale factors, such as the length of a motor to provide varying torque or the number of compressor stages in an aircraft engine as in the Rolls Royce RTM322 engine example.

Horizontal leveraging: conceptual/configurational scale factors, such as the size of evaporator in a family of air conditioners or the number of passengers carried by the Boeing 747 family of aircraft.

Beachhea dapproach: combination of parametric, conceptual, and/or configurational scale factors as needed.

Scale factor may be discrete or continuous, however, only a lot of research is a continuous. Describe each one of the factors used a range of appropriate. Other, determine the ranges are also a part of the design process. Determine the range of the known parameters, design parameters and system constraints parameters, as well as the calculation formula, equation and so on.

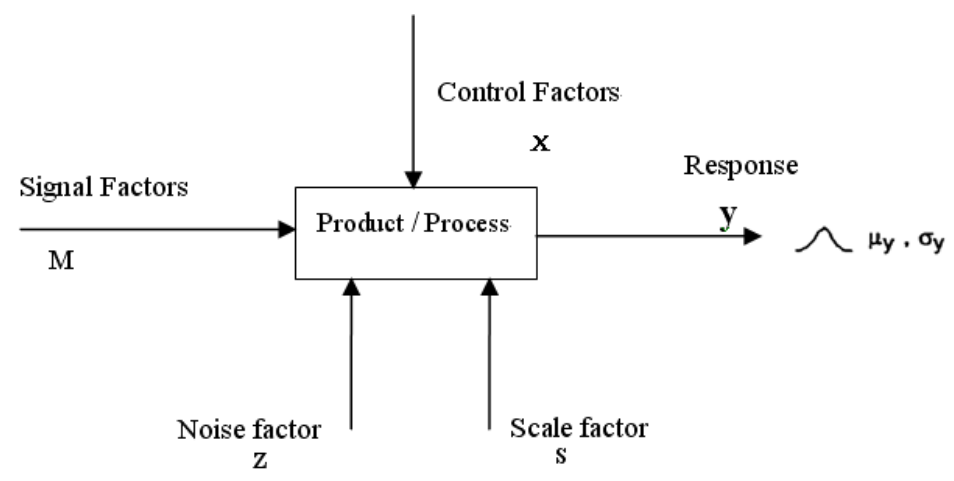

Fig. 3. Robust design with Scale factors

Step4: Analyze product structure, mapping design principal parameters to structure.

Function decomposition is needed before attribute-to-design principal parameters mapping. Using Function correlation analysis method, we can cluster analysis the differentiated products functional structure, form function module and then complete mapping of function module to product structure of the module. When the products structure is clear, by analysis of product variant mentioned above, the products public elements are determined. 
Step5: Set up a parameterized flexible product platform.

Extracting public elements and flexible elements from the parametric method, parameterized flexible product platform is gained. Upon this, by adding matching and variant design element, using the element of mutual constraint and rules, the product family which meets the market demand can be realized rapidly.

\section{Sample Analysis}

Belt conveyor uses the conveyor belt to drive and carry load, it can be working continuously used in material conveying through the movement of the conveyor belt. Conveyor belt bypass the drive roller and tail roller, forming an endless belt. The upper and lower conveyor belt are borne by belt idler to limit sag of the conveyor belt, at the same time, tensioning device provides the necessary tension for the normal operation of the conveyor belt. Drive device drives drive roller when working, the friction between the drive roller and conveyor belt makes the conveyor belt run, the objects on belt move together with it. The construction steps of flexible platform for belt conveyor are as follows:

\section{(1) Divide up the market grid}

By analyzing the market status of belt conveyor, we know the current market is mainly divided into three parts according to their throughput, they are lowthroughput, mid- throughput, and high- throughput. However, each part can be broadened horizontally according to the different width of conveyor belt, and can be divided into several series. Each series could also get a variety of variant products according to the length of conveyor belt, the height, the speed and so on. Through in depth research, the bandwidth of conveyor is divided into four scopes, they are $0.4 \sim$ $0.8 \mathrm{~m}, 0.8 \sim 1.2 \mathrm{~m}, 1.2 \sim 1.6 \mathrm{~m}$ and $1.6 \sim 1.8 \mathrm{~m}$. Figure 4 shows how to divide up the market grid.

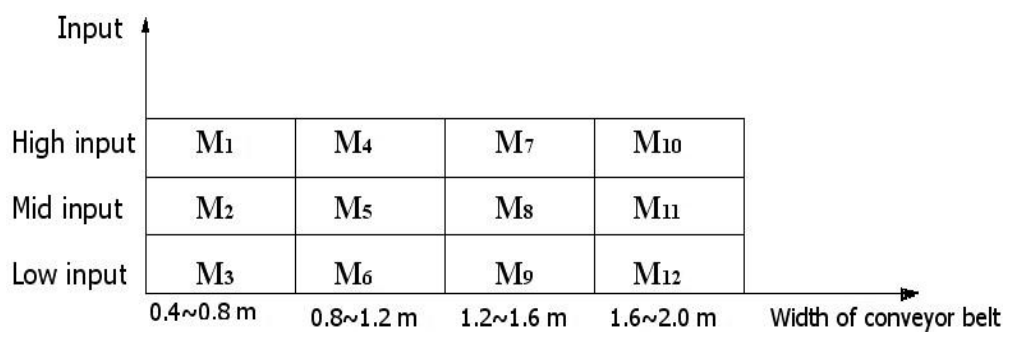

Fig. 4. The market segments of belt conveyor

(2) Analyze uncertainty and find the main parameters which determine the performance of belt conveyor, find out uncertainty factors.

When designing a belt conveyor, the main design parameters are width and speed of belt, belt idler size, roller size, bed size, the choice of tensioning devices and auxiliary equipment and so on. The factors which affect the width of belt are throughput, transmission angle, transmission speed and transmission intensity etc which are requested by users. The factors which affect the speed of belt are the changing in 
width of belt, throughput, transmission angle, and transmission intensity, etc requested by users. The factors which determine the diameter of drive roller are the changing in width and speed of belt. The factors which affect the diameter of belt idler are the changing in width and speed of belt too. It is obvious that all parameters are affected by bandwidth through the conclusions above, so the bandwidth is the main parameter of belt conveyor.

According to market analysis and advice brought out by experts, it is the first step to determine changing index (CVI) and coupling index (CI) using DFV. And then the desired changing curve of belt conveyor can be achieved according to CVI and CI. Finally, the optimal uncertainties of belt conveyor could be found according to the optimal trend, they are the width and speed of belt, the diameter of rollers, belt idler size and the height of bed, etc.

(3)Optimize uncertain factors, determine the range of uncertain factors, finally determine the bandwidth of belt conveyor platform, optimize the product family.

Using the design method of robust with scale factor brought out by Simpson, we can analysis the fluctuation range of bandwidth resulted from the changing in speed of belt, the diameter of rollers, belt idler size and so on, and determine typical parameter values of bandwidth when it is changing in different scales. The optimal design variables are shown as table 1.

Table 1. The optimal design variables

\begin{tabular}{cllcc}
\hline Series & $\begin{array}{c}\text { Band } \\
\text { width } \\
(\boldsymbol{m})\end{array}$ & $\begin{array}{c}\text { belt } \\
\text { speed } \\
(\boldsymbol{m} / \mathbf{s})\end{array}$ & $\begin{array}{c}\text { Drum } \\
\text { diameter } \\
(\mathbf{m m})\end{array}$ & $\begin{array}{c}\text { Roller } \\
\text { Diameter } \\
(\mathrm{mm})\end{array}$ \\
\hline 1 & 0.8 & 2.0 & 630 & 108 \\
1 & 0.8 & 2.5 & 800 & 108 \\
2 & 1.2 & 1.25 & 1000 & 133 \\
2 & 1.2 & 1.6 & 1250 & 133 \\
$\ldots$ & $\ldots$ & $\ldots$ & $\ldots$ & $\ldots$ \\
4 & 1.8 & 2.5 & 800 & 108 \\
$\mathbf{4}$ & 1.8 & 3.15 & 1000 & 108 \\
\hline
\end{tabular}

(4) Analysis the structure of belt conveyor, the main parameters in designing mapping to its structure.

Determining the common elements by analyzing each series of product. We find that only the module of conveyor belt is common, in the product family of belt conveyor, other modules are all affected by parameter changing or the needs form users in some degree. So take the belt module as a common element and establish its functional structure. (Shown as figure 5)

Map the main design parameters gotten in step 2 to the structure of belt conveyer. The mappings are distributed mostly because the main parameters determine most of the parts. The modules which are determined by the main parameters entirely are shown as flexible elements, and then analyze the remaining structure modules in order to identify matching elements and variant design elements. 


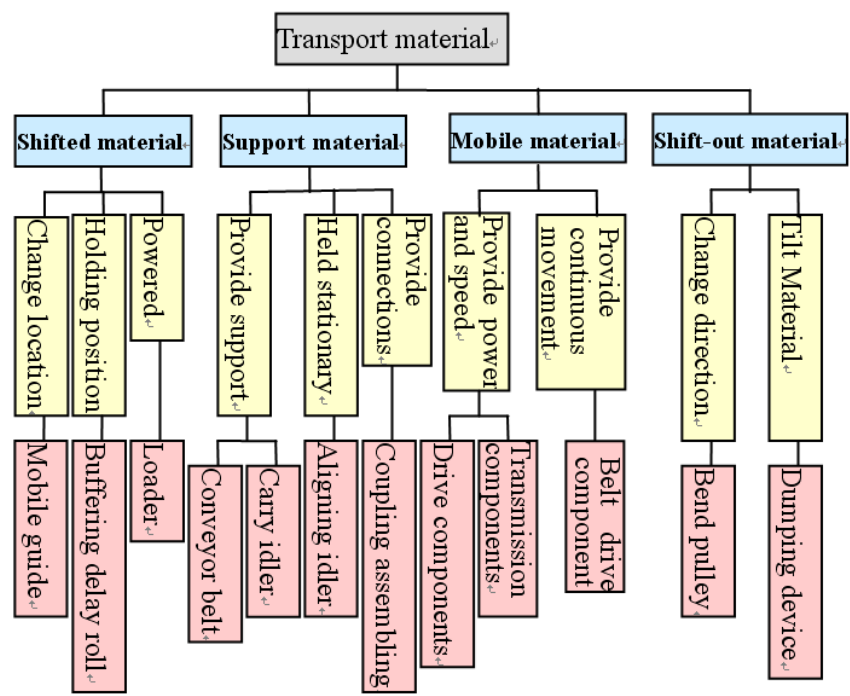

Fig. 5. Main functional tree of the belt conveyer

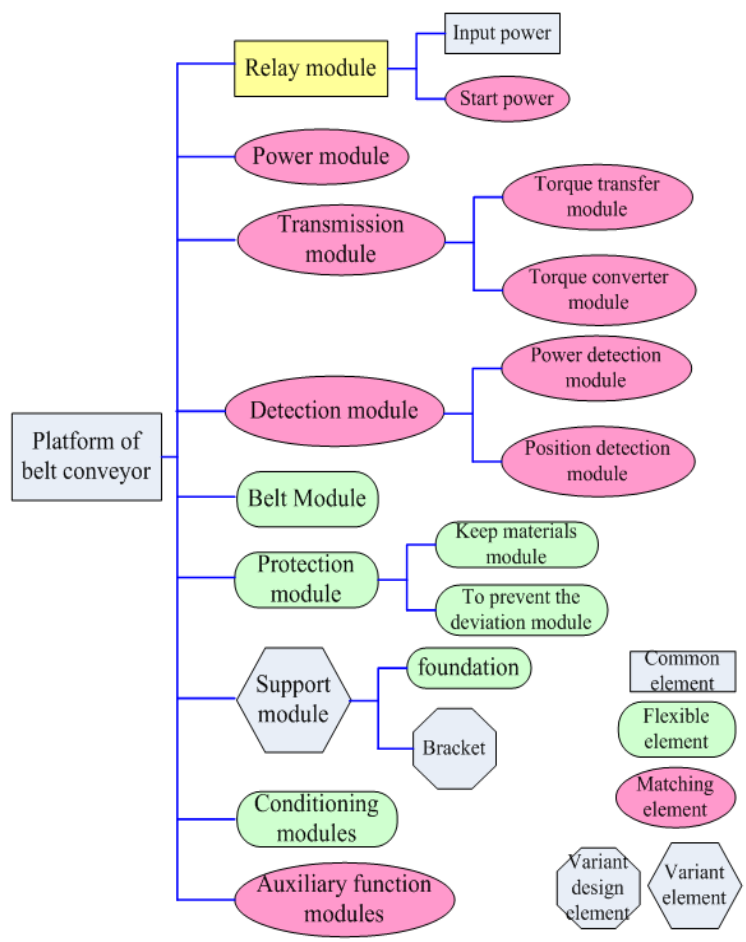

Fig. 6. The structure of parameterized flexible platform of belt conveyor 
(5) Establish parameterized flexible product platform of belt conveyor

The public elements and flexible elements achieved above are taken as the elements of flexible product platform of belt conveyor. As a result, designers only adjust the value of flexible elements in product platform when some certain product is needed by customers, and then determine the matching elements according to customers' demand, finally, re-design or analog design a fraction of variant parts. By using the constraint and rules among elements, designers can configure the product quickly according to user requirements and manufacture. The structure of parameterized flexible platform of belt conveyor is shown as figure 6 .

\section{Conclusion}

According to the research above, we have the following conclusions:

With increasing product variety and shorter development time, many companies are facing more and more complexity to develop new products. So this paper introduces a design method for flexible product platform based on parameterized.

This paper introduced a design process of parameterized flexible product platform. It begins at defining the market segments, product variants, and uncertainties. The uncertain factors are determined by the method of DFV. Parameterization is then embedded for establishing the product platform bandwidth.

Finally, a full-scale case study of product platform of belt conveyor was shown using parameterized flexible product platform.

\section{Acknowledgments}

This research is supported by the Project of Hebei Education Department (2009324, S090314), the Special Foundation for Basic Science-Technology of China (2009IM020700, 2010IM020100) and the Natural Science Foundation of China (70972050).

\section{References}

1. Zhao, L.: Parameter-product platform design and configuration method based on Parameter. Master thesis, Hebei University of Technology (2007)

2. Simpson, T.W.: A Concept Exploration Method for Product Family Design. Doctoral dissertation, Georgia Institute of Technology (1998)

3. Shi, K.: Research of the Configuration System of CNC Vertical Grinding Machine Based on Product Platform. Master thesis, Hebei University of Technology (2008)

4. Suh, E.S.: Flexible Product Platform. Doctoral dissertation, Massachusetts Institute of Technology (2005)

5. Martin, M.V.: Design for Variety. Master thesis, Stanford University Department of Mechanical Engineering (1999) 